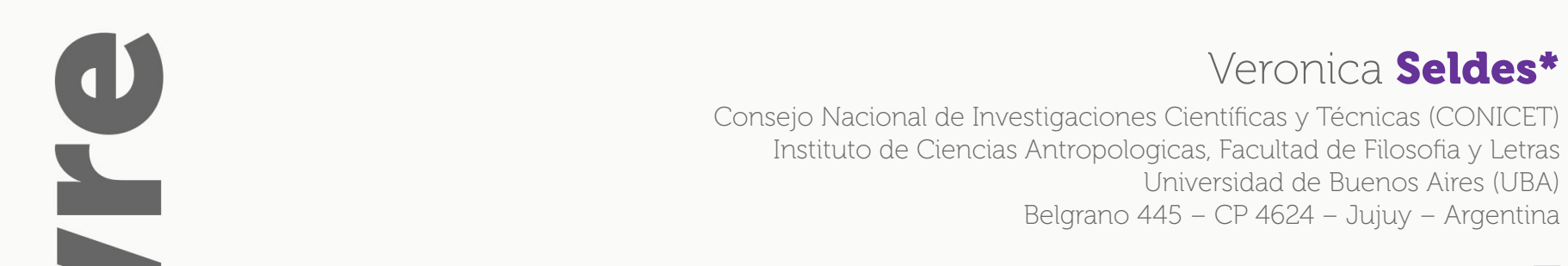

vseldesayahoo.com.ar

\title{
Prácticas mortuorias prehispánicas en Quebrada de Humahuaca (Jujuy, Argentina)
}

\author{
Pre-Hispanic mortuary practices in Quebrada de \\ Humahuaca (Jujuy, Argentina)
}

\begin{abstract}
RESUMEN
El objetivo de este trabajo es evaluar las prácticas mortuorias prehispánicas de los pueblos que vivieron en la Quebrada de Humahuaca (Jujuy, Argentina). Se consideran diferentes momentos de ocupación de la región, analizando si hubo variaciones a lo largo del tiempo en las expresiones materiales de los rituales funerarios. Esto brinda información no solo sobre los momentos de despedida de los difuntos, sino también sobre la cosmovisión del grupo y sus lógicas culturales. A través de la recopilación de investigaciones realizadas desde principios del siglo pasado, se registra la información sobre arquitectura funeraria y el acompañamiento mortuorio. Del análisis se desprende que algunas características como los entierros siendo parte de los espacios de uso cotidiano, se mantuvieron a lo largo del tiempo; mientras que el acompañamiento mortuorio registra cambios que dan cuenta de la dinámica de los procesos sociales de estos pueblos.
\end{abstract}

Palabras Clave: Arqueología funeraria - Prácticas sociales - Quebrada de Humahuaca - Culto a los ancestros

\begin{abstract}
This paper analyse pre-Hispanic mortuary practices of populations who lived in Quebrada de Humahuaca (Jujuy, Argentina), and consider different moments of occupation of the region, analyzing if there were variations in the material expressions of funeral rituals over time. It has provides information not only about the farewell moments of the deceased, but also in relation to the worldview and cultural logics of the group, reviewing collection of researched conducted since the beginning of the last century, information on funeral architecture and mortuary accompaniment. The analysis infers that some characteristics, such as burials being part of everyday spaces, were maintained over time. On the other hand, the mortuary accompaniment records changes, which reflect the dynamics of the social processes of these groups.
\end{abstract}

Keywords: Funerary archeology - Social practices - Quebrada de Humahuaca - The ancestor's cult

* Doctora en Arqueología por la Universidad de Buenos Aires. Investigadora del Consejo Nacional de Investigaciones Científicas y Técnicas (CONICET). Instituto Interdisciplinario de Tilcara, Facultad de Filosofía y Letras, UBA. CV: https://conicet-ar.academia.edu/VeronicaSeldes; https:// www.researchgate.net/profile/Veronica_Seldes2. 


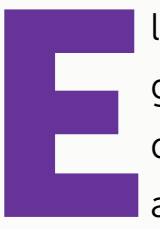

I tratamiento dado a los difuntos en los momentos del ritual funerario ha despertado gran interés desde los inicios de la arqueología. Sin embargo, su estudio fue variando de acuerdo a los marcos teóricos y metodológicos que predominaron en la disciplina a lo largo del tiempo (Seldes y Gheggi, 2016).

Hacia los comienzos de la arqueología en Argentina, y hasta mediados del siglo pasado, las excavaciones se centraban en gran medida en los contextos mortuorios ya que eran los espacios mejor conservados del registro arqueológico, principalmente debido a las características de estos espacios: claramente delimitados y muchas veces con tapas que permitían una buena preservación de su contenido. La modalidad de excavación consistía en esa época en recuperar principalmente el material de las tumbas, esto es, los restos óseos bien conservados y el acompañamiento para luego trasladarlos a las instituciones de pertenencia de los investigadores (diferentes museos como el Etnográfico J.B. Ambrosetti de la Facultad de Filosofía y Letras de la UBA y el Museo de La Plata de la Facultad de Ciencias Naturales y Museo de la UNLP). La característica de esta época es que se clasificaban y depositaban por separado las diferentes materialidades (cerámica, lítico, etc.) y los restos óseos, sin dejar registro escrito de los contextos de procedencia. Sumado a esto, los restos humanos eran separados en partes, sin referencias a las conexiones anatómicas ni a las relaciones de los cuerpos con las unidades funerarias de procedencia. Esto limitó en gran medida las posibilidades de aproximarnos al conocimiento de los contextos mortuorios y el significado de la muerte para los pueblos que habitaron la región en tiempos prehispánicos (Baffi, 1992).

Esos modelos teóricos esencialistas, evolucionistas en un comienzo y luego histórico culturales, describían a los pueblos prehispánicos a partir de una lista de rasgos que las definirían, buscando en la evidencia algunas características ya establecidas y que permitirían asignarla a clasificaciones previamente realizadas por reconocidos arqueólogos como Debenedetti (1910) para los comienzos de la disciplina e Imbelloni (1938) para momentos posteriores. Todos los hallazgos eran asignados a "culturas" determinadas de acuerdo a la lista de atributos de cada una.

Los modelos procesuales, surgidos a mediados del siglo pasado a nivel mundial, llegados con retraso a Argentina por lo consolidada de la Escuela Histórico - Cultural, cuestionaron el esencialismo imperante en la arqueología, pero conservaron cierta lógica universalista que terminaba encapsulando las posibilidades de aproximarse a la variabilidad que el mismo registro arqueológico estaba mostrando. De esta manera, postulaban como regla general que había una relación directa entre la riqueza del acompañamiento mortuorio, en la inversión de trabajo en los contextos mortuorios y el status social de la persona allí enterrada, esto es, que habría una relación isomórfica entre la energía invertida en el entierro de un individuo y la posición social que tenía en vida (Binford, 1971; Tainter, 1978).

El surgimiento de las llamadas arqueologías postprocesuales a partir de los años 90 , generó cambios en los marcos teóricos y las formas de abordaje del registro arqueológico y bioarqueológico. En este marco resurgen los contextos funerarios como eje de las investigaciones. Sin embargo, se continúa en ocasiones con modelos esencialistas cuando se propone "explicar" las prácticas mortuorias de una época o de una región sin considerar la 
heterogeneidad que se evidencia en el registro arqueológico (Seldes, 2012). De esta manera, los modelos universalistas, o panandinos en este caso, continúan sesgando las posibilidades de aprehender la complejidad de los procesos sociales, culturales, políticos y económicos de los pueblos. En este sentido y respecto al tema de los contextos mortuorios, se ha cuestionado la asociación directa entre las características de la tumba y el ajuar y el status social del difunto ya que se postula que tanto el tipo de entierro como el acompañamiento mortuorio responden en realidad a una variedad de causas como las dimensiones de la organización social (incluyendo en esto a la edad, el género y la posición vertical y horizontal del individuo) y a cuestiones vinculadas a las creencias acerca de la muerte, las enfermedades, la vida después de la muerte y el cosmos, entre otros (Carr, 1995).

Los aportes de los postulados derivados de la Teoría de la Práctica (Bourdieu, 1977) constituyeron un punto de inflexión para algunas problemáticas consideradas por la arqueología, el estudio de las prácticas mortuorias entre otras. Partiendo de la necesidad de centrarse en el individuo en tanto actor social/ agente, a efectos de superar las concepciones adaptativas de cultura y la pasividad de las personas frente a los cambios ambientales (Dobres y Robb, 2000; Seldes, 2009), se propuso tomar en consideración a los individuos en tanto agentes creadores o transformadores de su propia realidad (Miller y Tilley, 1984), creadores, recreadores y transformadores de la estructura social (Van Pool y Van Pool, 1999; Hodder, 1995; Pauketat y Alt, 2005). O en palabras de Brumfiel:

An agency perspective argues, however, that the impetus for at least some social changes was the desire of men and women to realize their (socially-determined) goals. Furthermore, an agency perspective argues that the timing of cultural change may be determined by evolving social circumstances rather than ecological conditions (Brumfiel, 2000, p. 251).

Siguiendo estas líneas de investigación se considera que las prácticas sociales puestas en juego en los rituales, en este caso los mortuorios, constituyen una de las esferas de interacción a través de las cuales se producen y reproducen relaciones sociales; como tales, acarrean historias, ideas y valores que estructuran y son estructuradas por los grupos humanos, esto es, actúan como generadores de prácticas y representaciones así como de la historia y memoria de ese grupo (Bourdieu, 1990).

En este sentido, siendo parte de las lógicas culturales de un grupo determinado, no habría significados unívocos y universales para las distintas prácticas sociales, que uno pueda transpolar de un contexto social, de una región y de un momento histórico determinado a otro (Fahlander y Oestigaard, 2008). Asimismo, de todos los rituales, los funerarios constituyen uno de los momentos más críticos para los familiares del difunto, para los allegados y para la sociedad en general ya que generan una serie de dispositivos que ponen en juego muchas cuestiones referidas a la reproducción y supervivencia de los grupos sociales. La preparación 
del espacio de entierro, la colocación de ofrendas, el tratamiento del cuerpo del difunto, aquello que conforman las prácticas mortuorias, requieren de una mirada integral que pueda contemplar la complejidad de las prácticas sociales en su propio marco de producción.

A partir de lo expuesto surge el interrogante acerca de cómo era vivida la muerte por parte de las poblaciones que habitaron la Quebrada de Humahuaca en épocas prehispánicas. Si bien desde la arqueología no es una pregunta de fácil abordaje, es posible aproximarnos a la forma en que un grupo se vincula con el acontecimiento de la muerte a través de los rituales funerarios (Brum Ribeiro, 2002). Es precisamente a través de la riqueza simbólica expresada en esos momentos que podemos aproximarnos a la cosmovisión del grupo y de sus lógicas culturales. Son los cuerpos, las ofrendas y el entorno cargados de significados los que pueden estudiarse desde la arqueología.

Los rituales pueden abordarse evaluando si cambiaron, al menos en su expresión material, a lo largo del tiempo. Por consiguiente, el objetivo de este trabajo es analizar las diferentes prácticas sociales frente a la muerte a lo largo del tiempo en la quebrada de Humahuaca (Jujuy, Argentina). El eje temporal corresponde a tres momentos de ocupación:

- Período Formativo (500 - 900 d.C.)

- Desarrollos Regionales I (900 -1250 d.C.)

- Desarrollos Regionales II (1250-1430 d.C.)

A tal efecto se combinarán la información que provee el estudio de las prácticas mortuorias desde diferentes líneas de evidencia: la arquitectura funeraria y el acompañamiento mortuorio.

\section{La Quebrada de Humahuaca}

Con una larga historia que se remonta desde hace por lo menos 10000 años (Aschero, 2000), la quebrada de Humahuaca se encuentra ubicada en el sector central de la provincia de Jujuy. Constituye un estrecho valle árido surcado por el Río Grande de Humahuaca (figura 1); tiene un recorrido $\mathrm{N}$ - S de casi $100 \mathrm{~km}$ y cuenta con zonas fértiles cerca de los recursos acuíferos con posibilidades del desarrollo de la agricultura limitadas por la aridez del paisaje (Cabrera, 1976; Albeck, 1992). 
Figura 1 - Ubicación de la Quebrada de Humahuaca

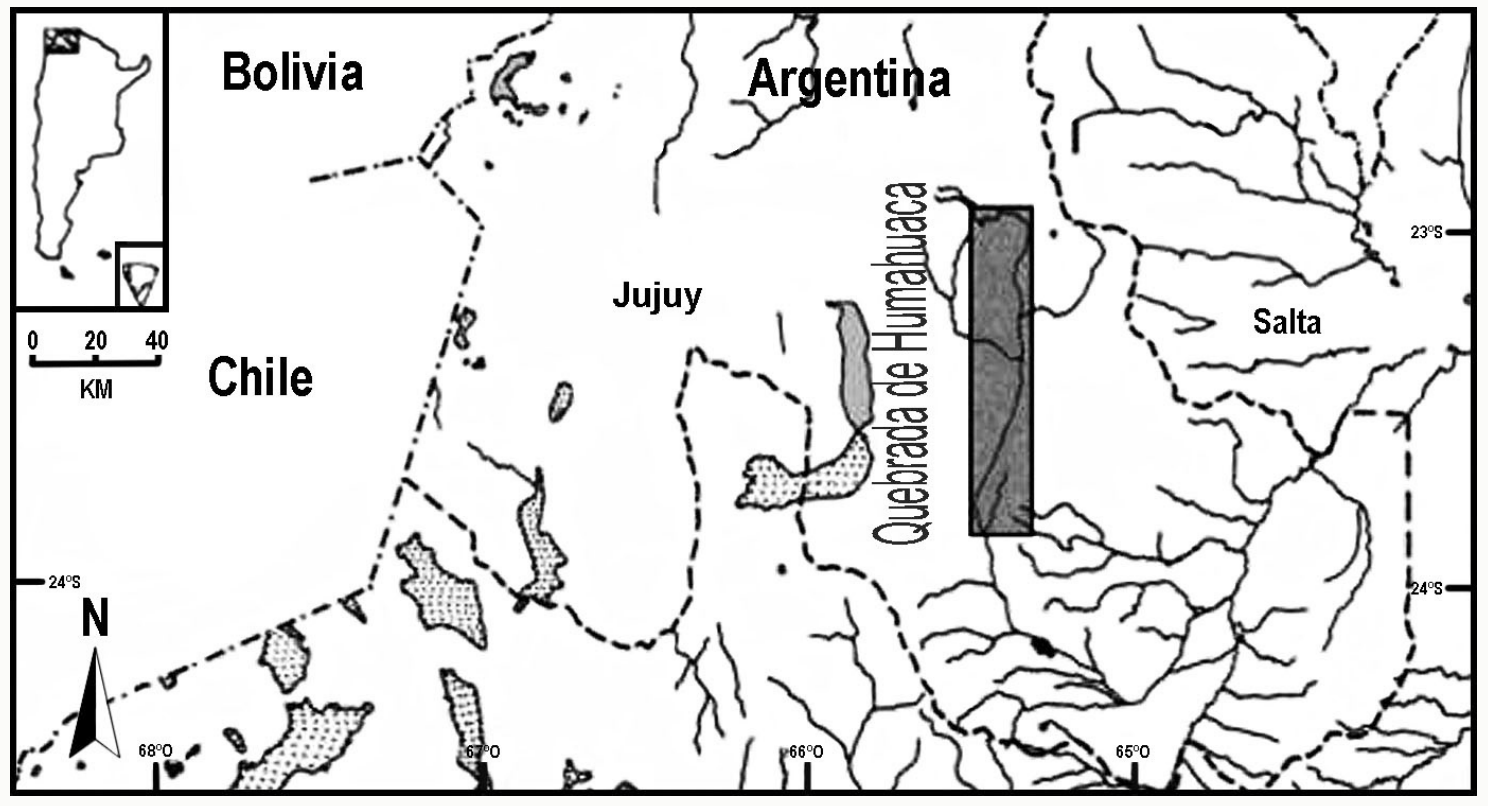

Fuente: Modificado de Angiorama (2001)

Siendo poco lo que se conoce para el período en el cual la región estuvo habitada por grupos cazadores - recolectores y por los primeros agricultores, este trabajo parte del período Formativo (500-900 d.C.), cuyas principales características se describen a continuación.

\section{Período Formativo (500 - 900 d.C.)}

Se trata de un momento en el cual las pocas poblaciones que habitaban la región vivían en poblados dispersos, cerca de los recursos, integrando las áreas habitacionales con los espacios agrícolas y ganaderos. Estaban organizados en comunidades pequeñas, similares entre sí entre las cuales no habrían existido controles políticos centralizados o desigualdades sociales estructurales (Nielsen, 2001). Los vínculos se guiaban por las relaciones de parentesco siguiendo las reglas establecidas por el sistema de organización en Ayllus, esto es, un sistema basado en grupos de familias extendidas que tenían el manejo colectivo de los recursos (Moseley, 2001). Los sitios de este período tienen baja visibilidad debido a que se encuentran en áreas fértiles donde la población se fue asentando a lo largo del tiempo. Por consiguiente, los hallazgos se realizan habitualmente en lugares como el actual pueblo de Tilcara, a partir de trabajos de arqueología de rescate en espacios habitados en la actualidad (Figura 2) lo que limita las posibilidades de recuperar información exhaustiva del período en cuestión. 
Figura 2 - Sítios Período Formativo

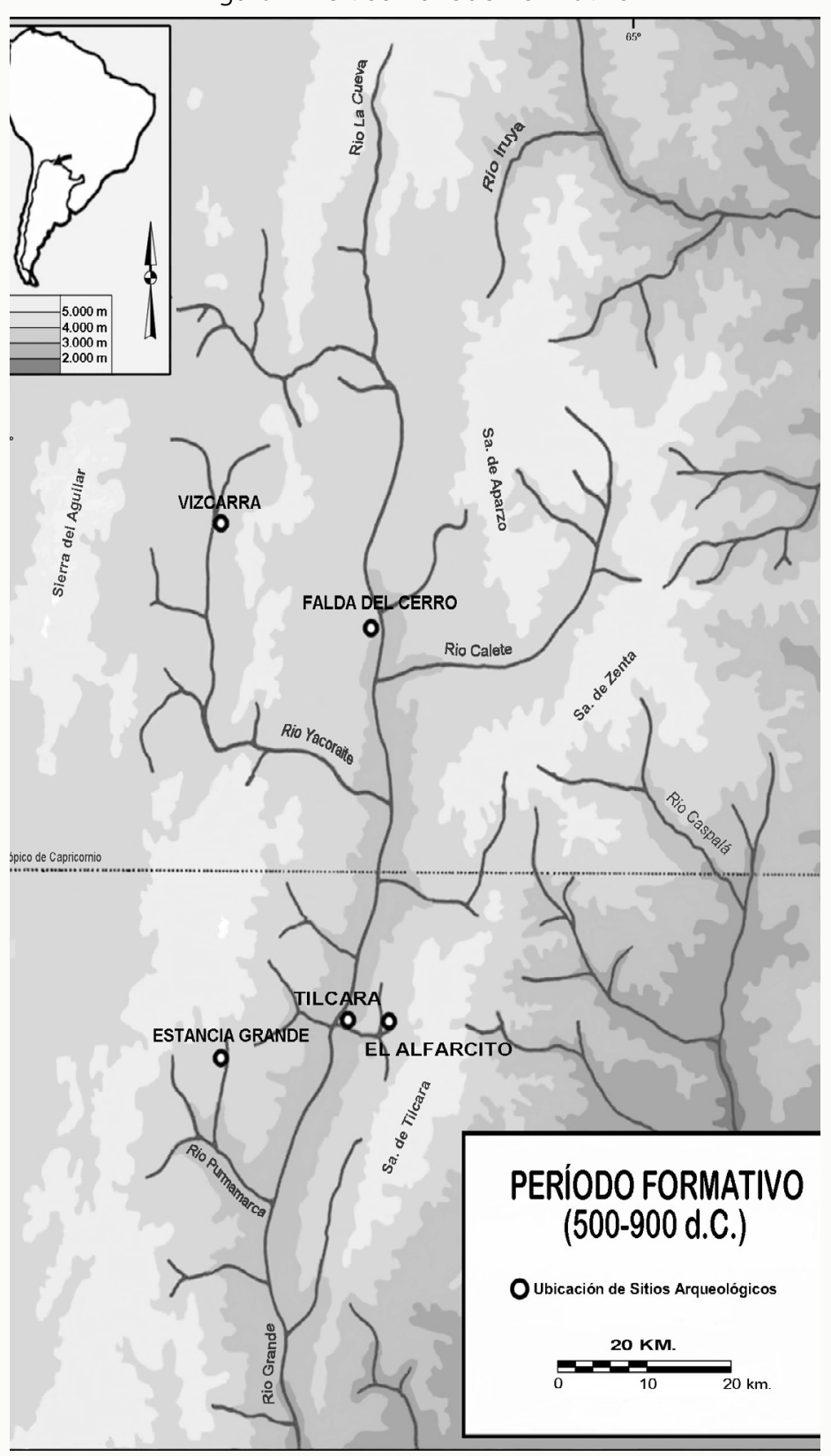

Fuente: Modificado de Nielsen (2001) 


\section{Periodo de Desarrollos Regionales (PDR) I (900 - 1250 d.C.)}

En este período se registran algunos cambios, especialmente en cuanto a las proporciones y ubicación de los poblados. En este sentido se observa un incremento en la cantidad de sitios (Figura 3) además de modificaciones en los asentamientos que ahora se encuentran más concentrados y con mayor densidad edilicia. A diferencia del período anterior, las áreas productivas se ubican separadamente de las domésticas. Aparecen algunas evidencias de cierto grado de conflictividad social como ser el hallazgo de cabezas - trofeo en sitios característicos de este momento como son La Isla y Keta Kara (Nielsen, 2001). Esto señala un momento de mayores niveles de violencia interpersonal aunque el registro bioarqueológico no da cuenta de un aumento en los niveles de traumas a nivel óseo (Seldes, 2007).

Figura 3 - Sitios Período de Desarrollos Regionales I

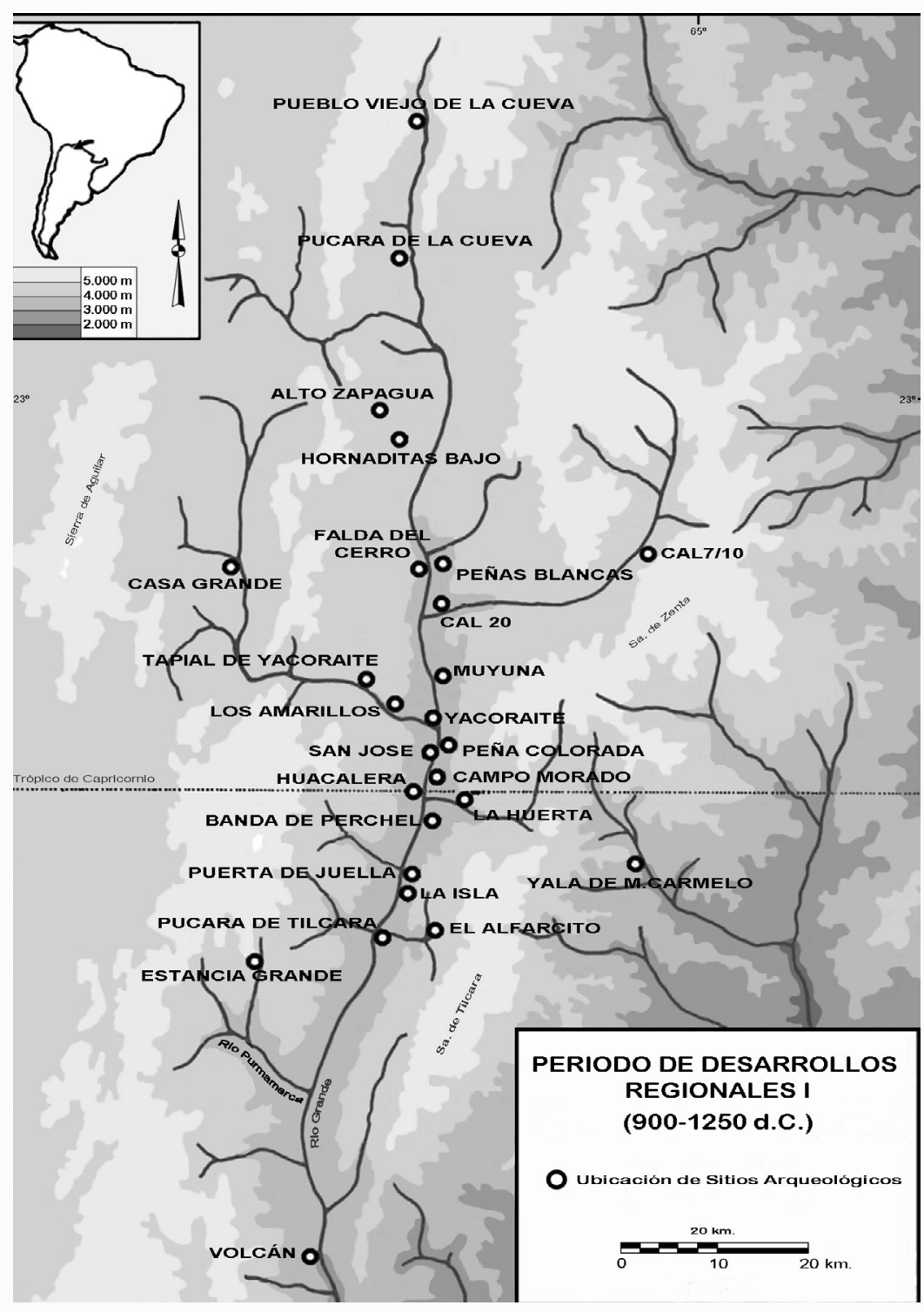

Fuente: Modificado de Nielsen (2001) 


\section{Periodo de Desarrollos Regionales II (1250 - 1430 d.C.)}

En el PDR II se registran nuevos cambios en la ubicación y tamaño de los asentamientos. La población se concentra en la quebrada troncal, en conglomerados ubicados en lugares de gran visibilidad y difícil acceso, los denominados Pucarás. ${ }^{1}$

La evidencia arqueológica refiere a situaciones de conflicto por el cual el período ha sido denominado "estado de guerra endémica" (Nielsen, 2015). Este conflicto podría derivarse de lo que se conoce como Anomalía climática medieval (Fritz et al., 2004; Shimada et al., 1991; Thompson et al., 1985), esto es, un ciclo de pronunciadas sequías que actuaron como disparadores de disputas en el acceso a los recursos y, con esto, de conflictos de carácter interregional. Es en este período cuando se consolida un sistema de organización social de tipo corporativo, como parte de nuevas prácticas políticas producto de la sensación de inseguridad provocada por los conflictos. Esto implica que las sociedades habrían generado mecanismos institucionales para regular el ejercicio del poder y restringir la acumulación económica por parte de una persona o grupo. El poder habría tenido carácter corporativo incluyendo una negociación constante de la posición con los demás miembros del grupo. Las principales formas de acumulación se basaban en capitales sociales y simbólicos más que económicos (Nielsen, 2006). Tampoco en este caso la evidencia bioarqueológica avala un aumento de la violencia interpersonal en comparación con períodos anteriores (Seldes, 2007).

1 Se denomina Pucara a grandes asentamientos con murallas defensivas, típicos del área andina prehispánica. Si bien los sitios arqueológicos de la región no poseen murallas, el nombre fue otorgado a grandes conglomerados ubicados en lugares estratégicos en cuanto a acceso y visibilidad. 
Figura 4 - Sitios Período de Desarrollos Regionales II

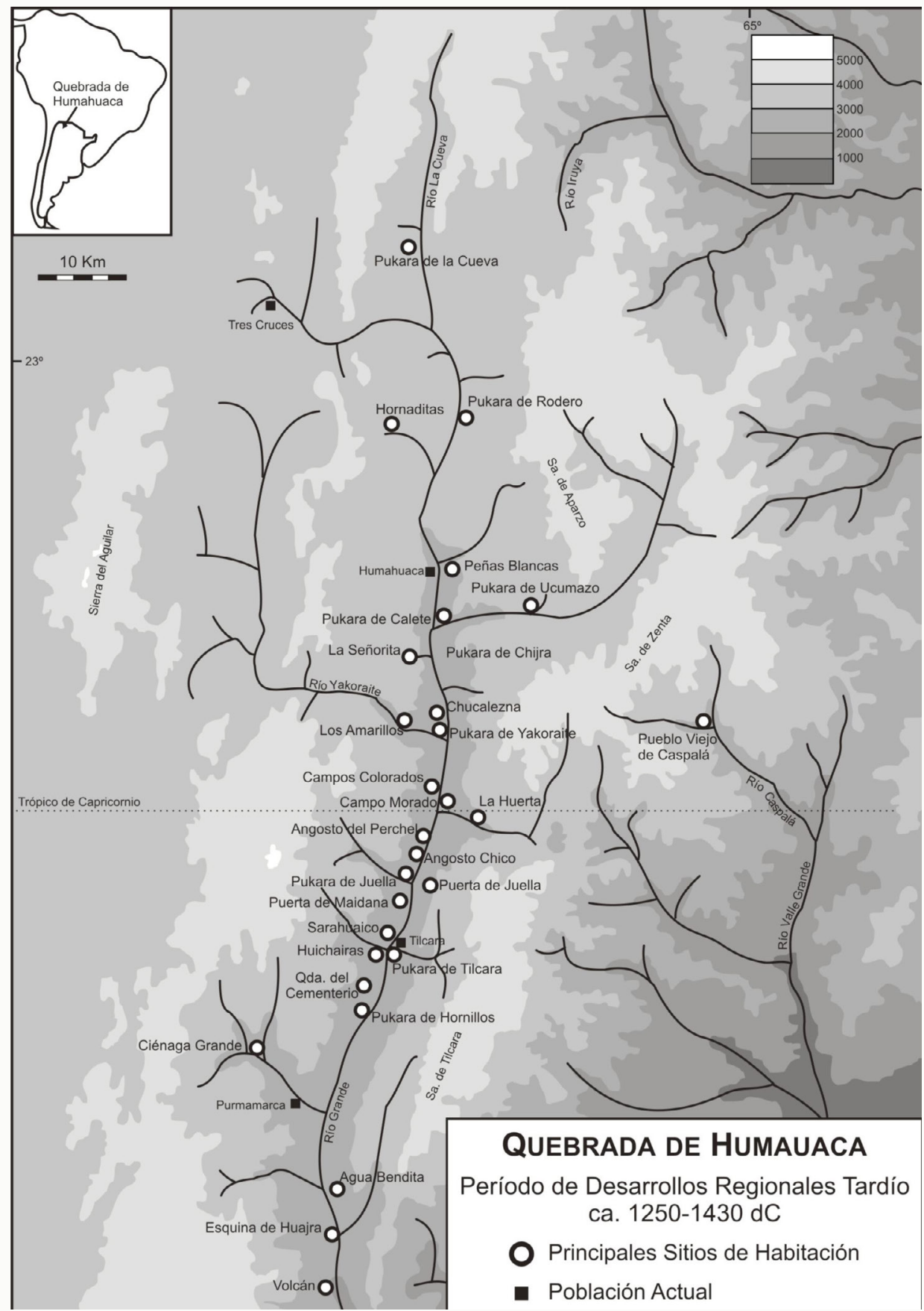

Fuente: Modificado de Nielsen (2001)

\section{Métodos}

Para el análisis de las prácticas mortuorias se relevaron las publicaciones realizadas por distintos investigadores a lo largo de los años, tomando en consideración aquellas que realizaran aportes concretos sobre los contextos funerarios en Quebrada de Humahuaca. Se trató de abarcar la mayor cantidad de información aunque seguramente algunas han quedado 
afuera del relevamiento realizado. Se tomó como referencia el trabajo de Seldes y Gheggi (2016) referido a las prácticas funerarias para la clasificación del acompañamiento mortuorio. Por otra parte se consideraron una serie de características de los entierros según se detalla a continuación:

- Ubicación: se consignó si se encontraban en espacios domésticos o en áreas destinadas especialmente al entierro de los difuntos.

- Tipo: los hallazgos se clasificaron de acuerdo a los típicos sepulcros en la región: en cámara, en urna, directo.

- Forma: se separaron en circulares y cuadrangulares.

- Tratamiento de los cuerpos: en este caso se asignaron al tipo de sepultura: entierro primario, secundario, remoción, en paquete.

- Cantidad de individuos: agrupando los entierros de acuerdo a si se había colocado un solo individuo (entierro simple) o más de uno (entierro múltiple).

\section{Resultados}

Los resultados se ordenan de acuerdo a la metodología explicada en el acápite anterior. En primer lugar se detallan los análisis realizados respecto al acompañamiento mortuorio, luego la ubicación y finalmente la forma, el tratamiento y la cantidad de individuos enterrados en cada espacio funerario. Se consideraron un total de 728 individuos, de los cuales 27 corresponden a 9 entierros del período Formativo, 165 individuos a 56 entierros del PDR I y 536 a 167 entierros del PDR II. Los resultados se vuelcan en la tabla 1.

Tabla 1 - Cantidad de entierros e individuos analizados

\begin{tabular}{|c|c|c|c|c|}
\hline \multirow{2}{*}{ Periodo } & \multicolumn{2}{|c|}{ Cantidad } & \multicolumn{2}{c|}{ Cantidad individuos } \\
\cline { 2 - 5 } & Entierros & Individuos & Adultos & Subadultos \\
\hline Formativo & 9 & 27 & 20 & 7 \\
\hline PDR I & 56 & 165 & 148 & 17 \\
\hline PDR II & 167 & 536 & 468 & 68 \\
\hline TOTAL & 232 & 728 & 636 & 92 \\
\hline
\end{tabular}

Fuente: Datos propios

\section{Acompañamiento mortuorio}

Para el análisis del acompañamiento mortuorio como se ha dicho en la sección metodología, se tomó como base el trabajo de Seldes y Gheggi (2016) donde se consideraron las siguientes categorías: 1. Cerámica decorada y no decorada, 2. Puntas de proyectil, 3. 
Instrumentos líticos, 4. Cuentas de Collar, 5. Textiles, 6. Arqueofauna, 7. Artefactos de hueso, 8. Tabletas y tubos de inhalar, 9. Cestería, 10. Piezas de oro, 11. Instrumentos de Metal, 12. Otros. A partir de esto se elaboraron tablas para cada período que resumieran la información de los diferentes sitios analizados.

\section{Período Formativo final:}

La información proviene de tres trabajos de arqueología de rescate en el actual pueblo de Tilcara: Arroyo (Madrazo, 1968), Til $20^{2}$ (Bordach et al., 1999; Mendonça et al., 1991 y 2002) y Flores 1 (Seldes, 2007).

Tabla 2 - Acompañamiento Mortuorio Período Formativo

\begin{tabular}{|c|c|c|c|c|c|c|c|c|c|c|c|c|c|c|c|c|}
\hline \multirow{2}{*}{ Sitio } & \multirow{2}{*}{ En } & \multicolumn{2}{|c|}{$N$} & \multicolumn{13}{|c|}{ Acompañamiento } \\
\hline & & $A$ & $\mathrm{~S}$ & $\mathrm{Ce}$ & $P$ & $\mathrm{Li}$ & $\mathrm{Cu}$ & Te & $\mathrm{Ar}$ & Ah & $\mathrm{Tt}$ & $\mathrm{Ct}$ & Or & Im & Ot & $\mathrm{T}$ \\
\hline Arroyo & 1 & 4 & 1 & - & - & - & 1 & - & - & - & - & - & - & - & - & 1 \\
\hline Flores & 2 & 4 & 2 & - & 3 & - & 2 & - & - & - & - & - & - & 1 & - & 6 \\
\hline Til 20 & 6 & 12 & 4 & 1 & 8 & - & 1 & - & - & - & - & - & - & 2 & 1 & 13 \\
\hline TOTAL & 9 & 20 & 7 & 1 & 11 & - & 4 & - & - & - & - & - & - & 3 & 1 & 20 \\
\hline
\end{tabular}

Referencias: En: número entierro; N: cantidad de individuos por tumba; A: adulto; S: subadulto; Ce: cerámica; P: puntas de proyectil; Li: instrumentos líticos; Cu: cuentas de collar; Te: textiles; Ar: arqueofauna; Ah: artefactos de hueso; Tt: tabletas y tubos de inhalar; Ct: cestería; Or: Objetos de oro; Im: instrumentos de metal; Ot: otros; T: total de acompañamiento.

Fuente: Datos propios

En este caso son pocos los contextos disponibles para su análisis; sin embargo es posible observar (Tabla 2) que el acompañamiento más representado son las puntas de proyectil (55\% del total de acompañamiento) (Figura 6) siendo que prácticamente no hay piezas cerámicas. Luego de las puntas, son las cuentas de collar y los instrumentos de metal los grupos que tienen algún tipo de presencia. La metalurgia consiste en 2 brazaletes y un anillo (Figura 5). Es así que, el segundo grupo más representado es el de los adornos corporales.

2 En un trabajo anterior (Seldes y Gheggi, 2016) no se habían podido reconstruir los contextos funerarios de Til 20 , esto pudo ser resuelto combinando las diferentes publicaciones sobre el rescate arqueológico realizado en el lugar. 
Figura 5 - Brazalete - Sitio Flores

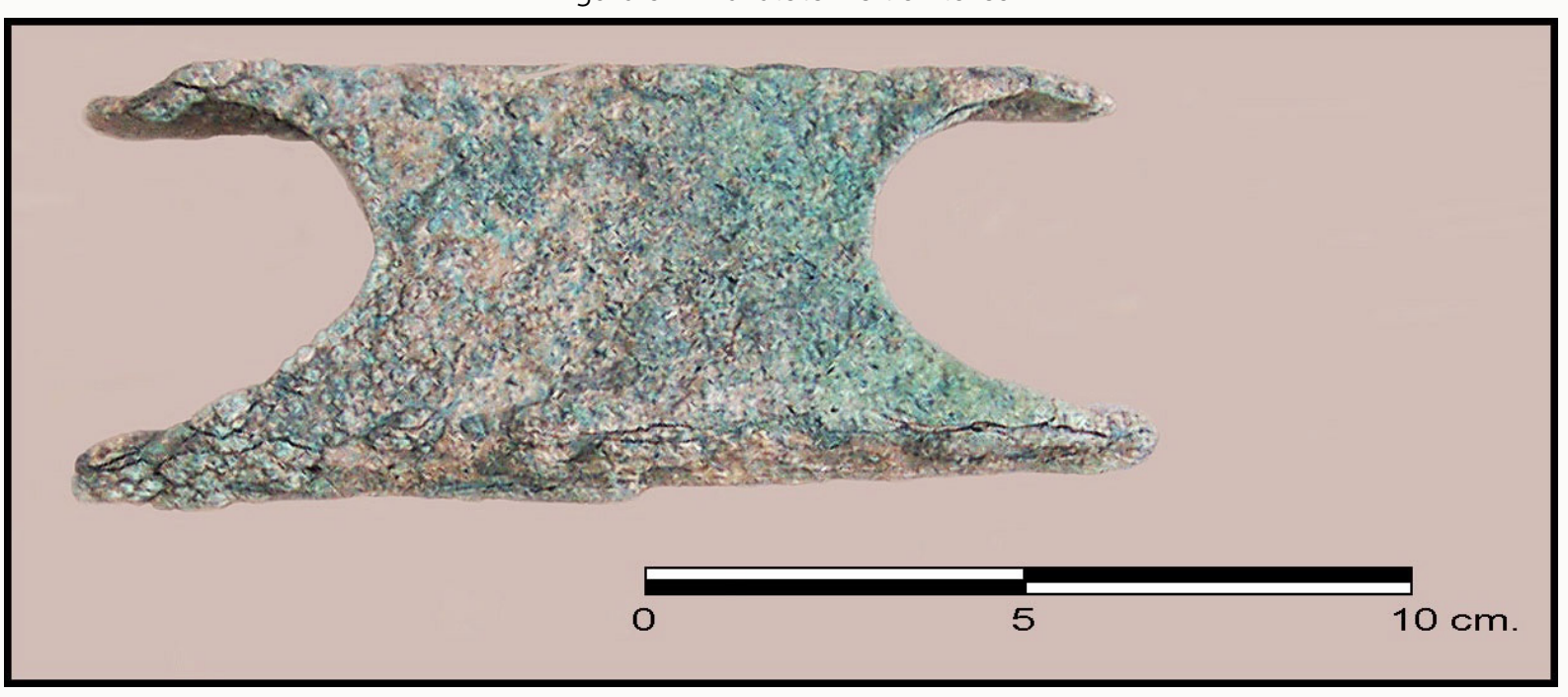

Fuente: Modificado de Seldes (2007)

Figura 6 - Puntas de proyectil - Sitio Flores

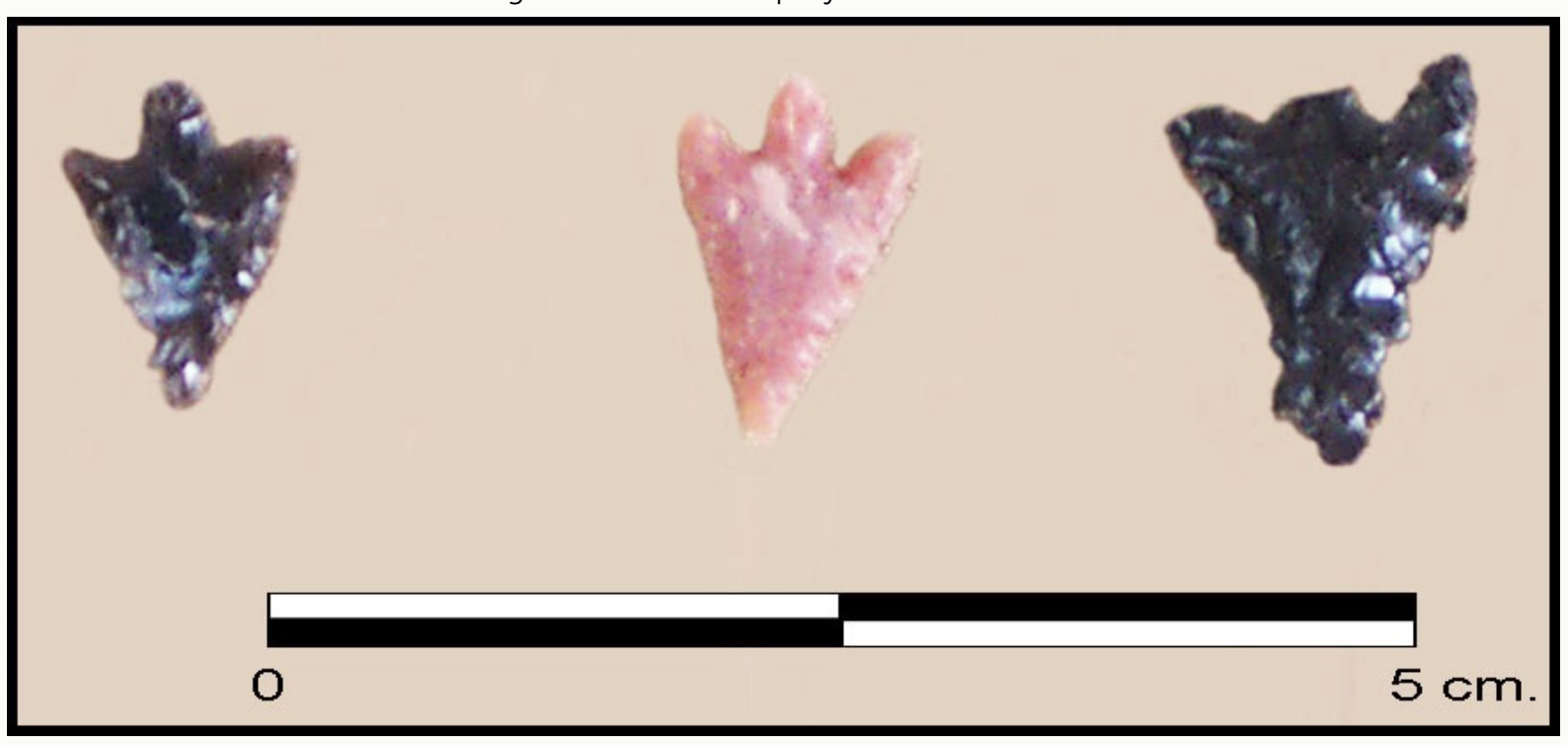

Fuente: Modificado de Seldes (2007)

PDRI

Para este período se cuenta con información de tres sitios: Muyuna (Seldes, 2007), Keta Kara (Pelissero, 1995) y La Isla (Debenedetti, 1910). 
Tabla 3 - Acompañamiento Mortuorio PDR I

\begin{tabular}{|c|c|c|c|c|c|c|c|c|c|c|c|c|c|c|c|c|}
\hline \multirow{2}{*}{ Sitio } & \multirow{2}{*}{ En } & \multicolumn{2}{|c|}{$\mathrm{N}$} & \multicolumn{13}{|c|}{ Acompañamiento } \\
\hline & & A & $\mathrm{S}$ & $\mathrm{Ce}$ & $P$ & $\mathrm{Li}$ & $\mathrm{Cu}$ & $\mathrm{Te}$ & $\mathrm{Ar}$ & Ah & $\mathrm{Tt}$ & $\mathrm{Ct}$ & Or & $\operatorname{Im}$ & Ot & $\mathrm{T}$ \\
\hline Muyuna & 7 & 10 & 5 & 2 & 3 & - & 2 & 1 & 1 & 5 & 3 & 2 & - & - & 3 & 22 \\
\hline Keta Kara & 19 & 55 & 10 & 24 & - & - & 1 & - & - & - & - & - & - & - & 1 & 26 \\
\hline La Isla & 30 & 83 & 2 & 332 & 2 & 7 & 9 & 1 & 7 & 23 & - & - & 33 & 6 & 14 & 434 \\
\hline TOTAL & 56 & 148 & 17 & 358 & 5 & 7 & 12 & 2 & 8 & 28 & 3 & 2 & 33 & 6 & 18 & 482 \\
\hline
\end{tabular}

Referencias: En: número entierro, N: cantidad de individuos por tumba, A: adultos, S: subadultos, Ce: cerámica, P: puntas de proyectil, Li: instrumentos líticos, Cu: cuentas de collar, Te: textiles, Ar: arqueofauna, Ah: artefactos de hueso, Tt: tabletas y tubos de inhalar, Ct: cestería, Or: Objetos de oro, Im: instrumentos de metal, Ot: otros; T: total de acompañamiento.

Fuente: Datos propios

De acuerdo a la tabla 3, se registraron un total de 482 elementos acompañando a los difuntos en las sepulturas. De los 56 entierros, 18 no tienen ningún tipo de acompañamiento lo cual representa el 32.14\% del total. Las piezas de cerámica fueron la ofrenda más representada (74\%). En este período aparecen objetos de oro aunque en baja proporción (7\%), siendo el segundo grupo más frecuente entre el acompañamiento mortuorio de los difuntos de este período. Es interesante que, con excepción de la cerámica, el resto de las ofrendas se encuentran en frecuencias muy bajas (gráfico 1).

Gráfico 1 - Acompañamiento mortuorio PDR I

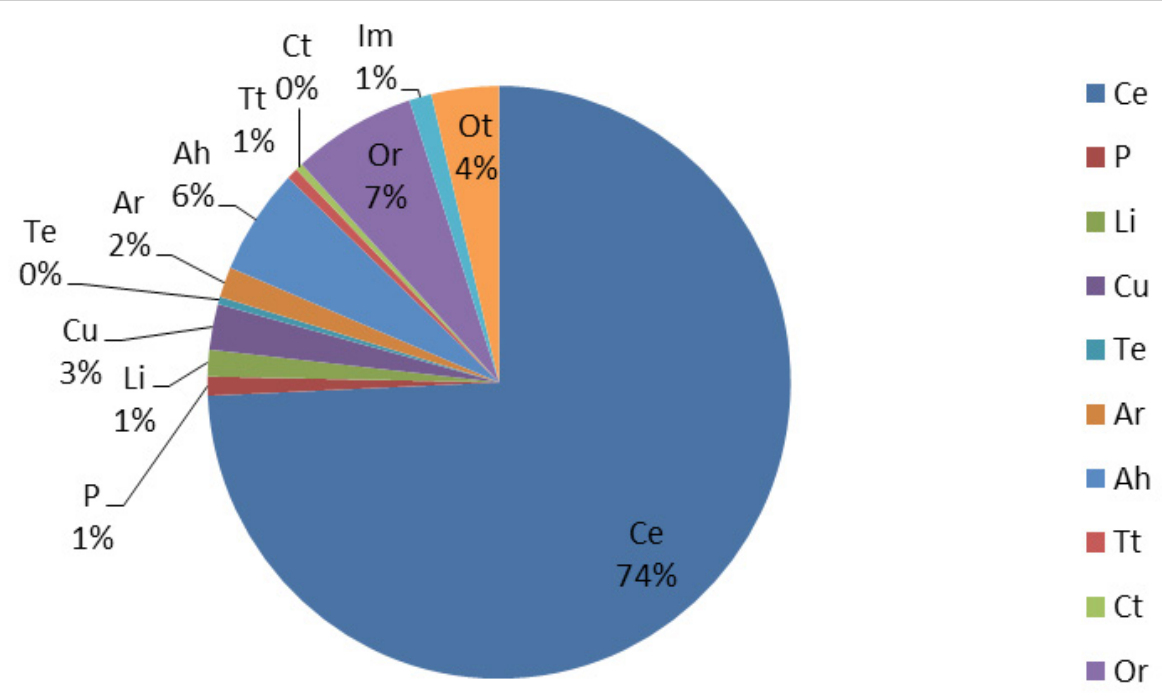

Fuente: Datos propios

Un punto interesante lo constituye las desiguales representaciones del acompañamiento mortuorio entre los sitios, siendo La Isla el que más ofrendas tiene en prácticamente todos los rubros pero especialmente en la cerámica, siendo las diferencias muy grandes entre este sitio y el resto. En este punto hay que resaltar el caso de la tumba 11 de La Isla que tiene 1 
individuo con 64 piezas de cerámica y 25 de oro, lo cual resalta por la cantidad de ofrendas que acompañan al difunto (Seldes y Gheggi, 2016).

Figura 7 - Cerámica. Sitio La Isla

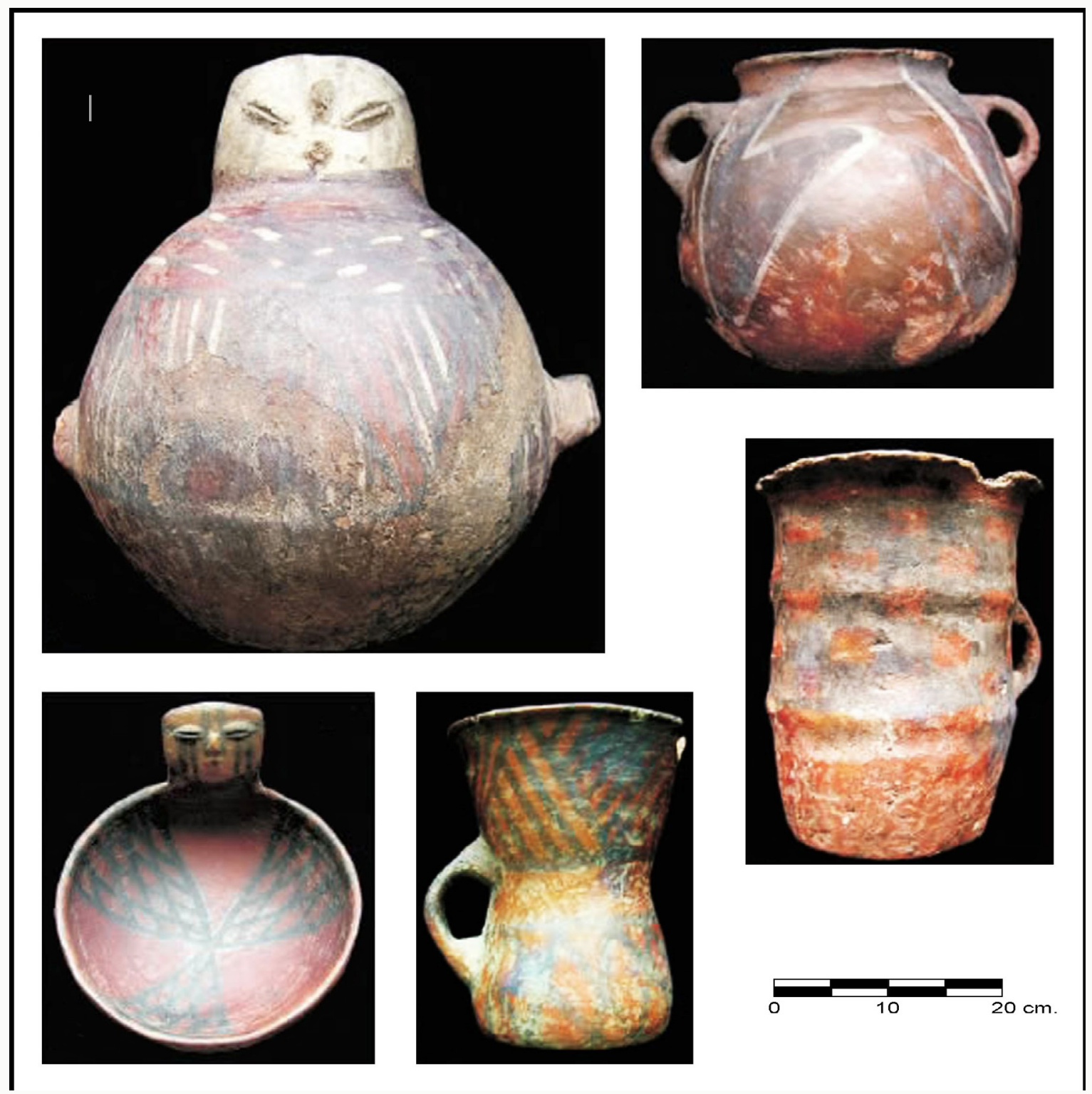

Fuente: Modificado de Yacobaccio (2012)

\section{PDR II}

En este caso hay mayor cantidad de información que provienen de diversos sitios del período (Tabla 4): Juella (Cigliano, 1967; Pelissero, 1969), Yacoraite (Palma, 1993), Los Amarillos (Palma, 1993; Nielsen y Walker, 1999; Seldes, 2012), Peñas Blancas (Gatto, 1946; Palma, 1993), Pucará de la Cueva (Casanova, 1933), Ciénega Grande (Salas, 1945), Campo Morado (Palma, 1993), La Huerta (Palma, 1997/98) y Pucará de Tilcara (Debenedetti, 1930). 
Tabla 4 - Acompañamiento Mortuorio PDR II

\begin{tabular}{|c|c|c|c|c|c|c|c|c|c|c|c|c|c|c|c|c|}
\hline \multirow{2}{*}{ Sitio } & \multirow{2}{*}{ Ent } & \multicolumn{2}{|c|}{ N } & \multicolumn{13}{|c|}{ Acompañamiento Mortuorio } \\
\hline & & A & S & $\mathrm{Ce}$ & $P$ & $\mathrm{Li}$ & $\mathrm{Cu}$ & $\mathrm{Te}$ & Ar & $A h$ & $\mathrm{Tt}$ & $\mathrm{Ct}$ & Or & Im & Ot & $\mathrm{T}$ \\
\hline Juella & 28 & 70 & 15 & 13 & - & 3 & 1 & - & 1 & - & 1 & - & - & - & 6 & 25 \\
\hline Yacoraite & 26 & 72 & 5 & 83 & - & 4 & - & - & 1 & 4 & 5 & - & - & 13 & 33 & 143 \\
\hline Los Amarillos & 6 & 148 & 6 & 31 & - & - & 1 & 1 & 1 & 8 & 5 & - & - & 1 & 26 & 74 \\
\hline Peñas Blancas & 26 & 52 & 6 & 51 & - & 1 & - & - & - & 6 & - & - & - & - & 4 & 62 \\
\hline Pucara de la Cueva & 3 & 4 & - & 4 & - & 4 & - & 1 & - & - & - & - & - & - & 2 & 11 \\
\hline Ciénega Grande & 16 & 17 & 5 & - & - & - & - & - & - & - & - & - & - & - & - & - \\
\hline Campo Morado & 7 & 16 & 2 & 19 & - & - & - & - & - & 6 & - & - & - & - & 19 & 44 \\
\hline La Huerta & 25 & 44 & 14 & 17 & - & - & 2 & - & 1 & 8 & - & - & - & 1 & 20 & 49 \\
\hline Pucara de Tilcara & 30 & 45 & 15 & 57 & - & - & 1 & - & 1 & 9 & - & - & - & 1 & 16 & 85 \\
\hline TOTAL & 167 & 468 & 68 & 275 & - & 12 & 5 & 2 & 5 & 41 & 11 & - & - & 16 & 126 & 493 \\
\hline
\end{tabular}

Referencias: En: número entierro, N: cantidad de individuos por tumba, A: adultos, S: subadulto, Ce: cerámica, P: puntas de proyectil, Li: instrumentos líticos, Cu: cuentas de collar, Te: textiles, Ar: arqueofauna, Ah: artefactos de hueso, Tt: tabletas y tubos de inhalar, Ct: cestería, Or: Objetos de oro, Im: instrumentos de metal, Ot: otros; T: total de acompañamiento.

Fuente: Datos propios

Gráfico 2 - Acompañamiento Mortuorio PDR II

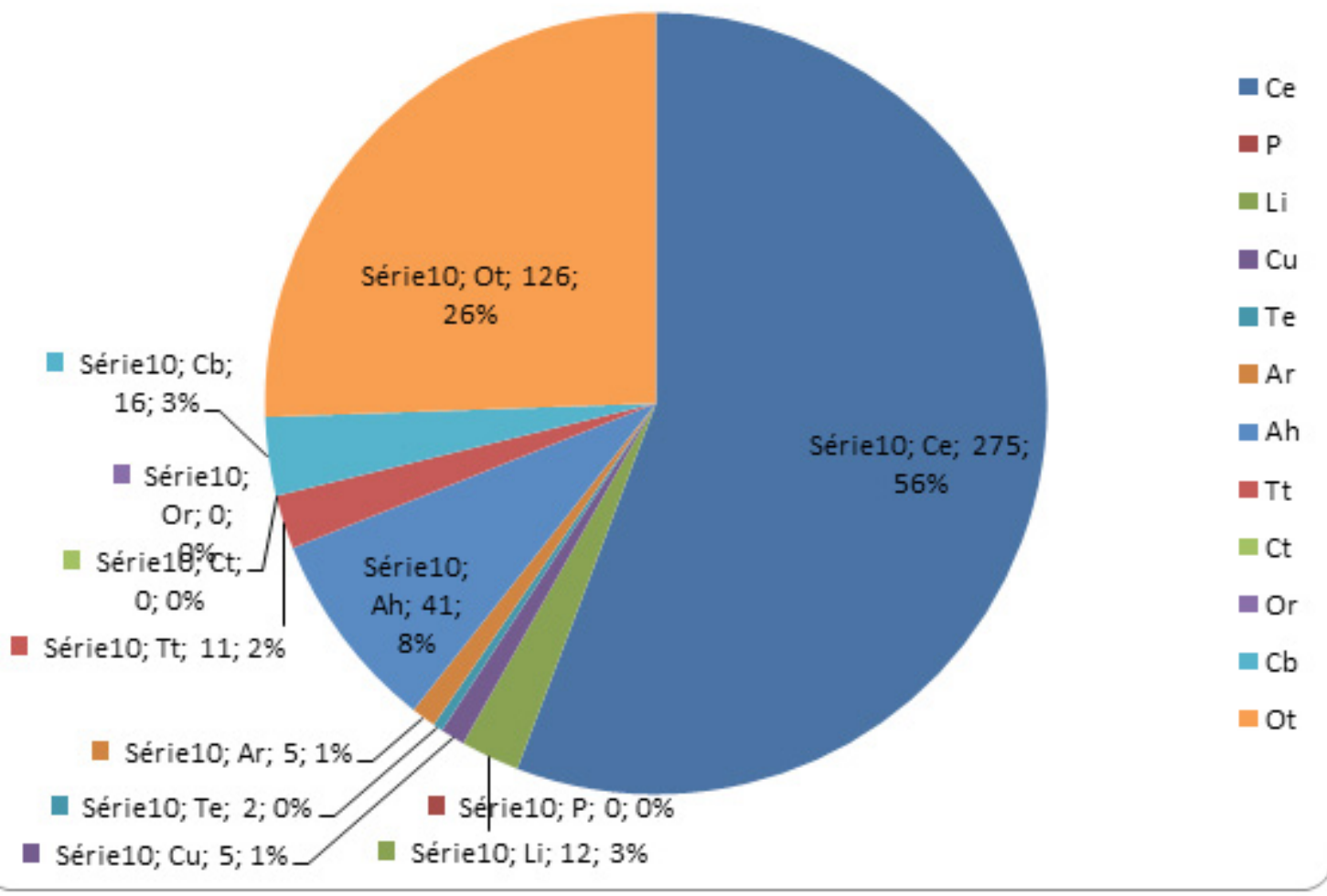

Fuente: Datos propios 
De acuerdo a la tabla 4 y gráfico 2, para este período, de los 167 entierros analizados, se observa que la mitad del acompañamiento lo constituyen las piezas cerámicas (56\%). El segundo grupo más representado es la categoría otros que incluye instrumentos de madera en su mayoría aunque se hallaron calabazas y cascabeles. A continuación las categorías más representadas son los instrumentos líticos seguido de cuentas de collar, artefactos de hueso y tabletas y tubos de inhalar (Gráfico 2 y Figura 8). Es en Yacoraite, Peñas Blancas y el Pucará de Tilcara donde hay mayor cantidad de ofrendas de cerámica, siendo Yacoraite el que mayor acompañamiento mortuorio tiene de todos los sitios analizados aquí.

Figura 8 - Tableta de Inhalar. Sitio Los Amarillos

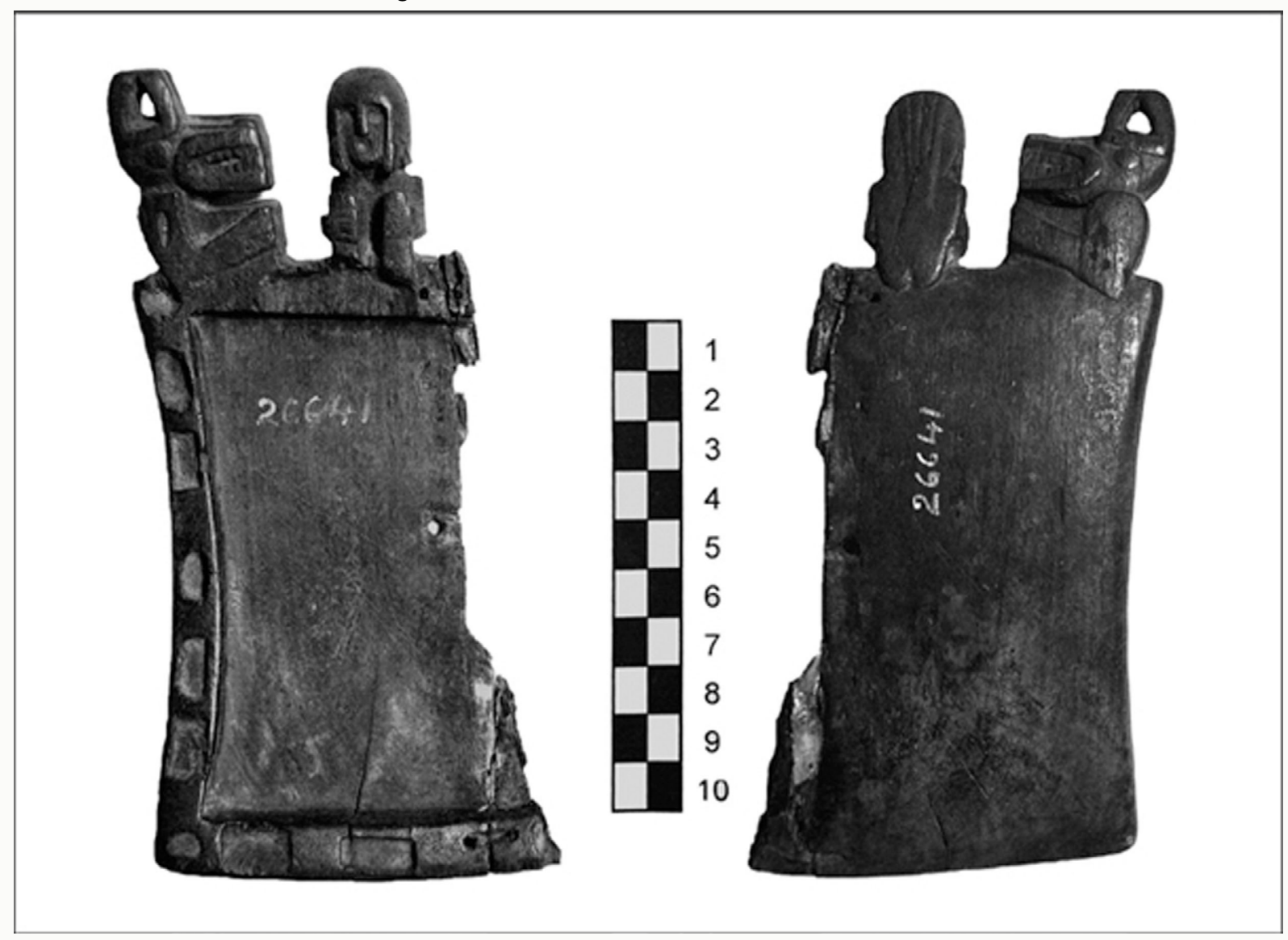

Fuente: Tomado de Horta Tricallotis (2012)

\section{Ubicación entierros}

Período Formativo: la posibilidad de recuperar información contextual sobre la ubicación de los espacios de entierros para este período se dificulta por el hecho de que los asentamientos están por debajo de las ocupaciones actuales, en el pueblo de Tilcara por ejemplo; por consiguiente, son esporádicas las excavaciones sistemáticas que han podido realizarse y que, además, se haya recuperado información que permita inferir fehacientemente 
si existían espacios segregados para el entierro de los difuntos. Sin embargo, hasta el momento pareciera que todos los entierros de este período fueron realizados en espacios domésticos (Nielsen, 2001; Zaburlín et al., 2006).

PDRI: De acuerdo a las investigaciones realizadas, los hallazgos de este período remiten a entierros en espacios domésticos. Si bien Debenedetti (1910) postulaba que en el sitio La Isla había hallado al menos dos necrópolis, trabajos posteriores han concluido que estos espacios no constituían áreas únicas de entierro sino que convivían con recintos de uso doméstico (Rivolta, 2000).

PDR II: en este período aparecen por primera vez en la región, áreas segregadas para el entierro de los difuntos: Pucará de Volcán y Pucará de Tilcara (Nielsen, 2001). Se trata de espacios utilizados solamente como cementerios y se encuentran localizados en las laderas de estos conglomerados. Salvo estos dos casos, los entierros en los más de 30 asentamientos conocidos para la época, continuaron realizándose en ámbitos domésticos.

\section{Tipos de entierros}

Formativo final: en los 9 entierros analizados, se registra cierta diversidad ya que 4 fueron realizados en cistas, o sea, "cámaras con bóveda en saledizo o falsa bóveda, con cierres de lajas y clastos" (Mendonça et al., 1991, p. 35). También se registran entierros directos, 3 en este caso, en espacios que no están especialmente preparados para el entierro de los difuntos, salvo alguna laja sosteniendo lateralmente los cuerpos. Por último se hallaron urnas donde se depositaban a los niños fallecidos (Tabla 5). Estas urnas no son las conocidas como "funerarias", elaboradas exclusivamente con la función de albergar los cuerpos, sino que se trata de grandes ollas iguales a las que se utilizaban cotidianamente para la cocción de los alimentos.

Respecto a la cantidad de individuos enterrados en cada espacio, en su mayoría se trata de entierros múltiples, esto es, donde se depositaban dos o más individuos fallecidos (Tabla 5). Los difuntos eran inhumados en posición genuflexa, característica que se mantiene para todos los períodos aquí analizados.

Tabla 5 - Tipos entierro Período Formativo

\begin{tabular}{|c|c|c|c|c|c|c|}
\hline \multirow{2}{*}{ Sitio } & \multicolumn{2}{|c|}{ Entierro } & \multicolumn{3}{c|}{ Tipo } & \\
\cline { 2 - 6 } & Simple & Múltiple & Cista & Directo & Urna & TOTAL \\
\hline Arroyo & - & 1 & 1 & - & - & 1 \\
\hline Flores & - & 2 & - & 1 & 1 & 2 \\
\hline Til 20 & 1 & 5 & 3 & 2 & 1 & 6 \\
\hline TOTAL & 1 & 8 & 4 & 3 & 2 & 9 \\
\hline
\end{tabular}

Fuente: Datos propios

PDR I: De los 56 entierros (Tabla 6), 67.86\% son múltiples (38 entierros) y en su mayoría directos (67.86\%), registrándose pocos casos de entierros en urna (3.57). Por otra parte es interesante lo que remarcan las investigaciones en el sitio Muyuna y La Isla sobre el hecho que 
los entierros directos no presentan ningún tipo de estructura ni preparación previa salvo que han sido sellados con una capa de barro (Nielsen, 2001). En este sentido Keta Kara difiere del resto ya que se trata de entierros en cistas.

Tabla 6 - Tipos entierro Período PDR I

\begin{tabular}{|l|c|c|c|c|c|c|}
\hline \multirow{2}{*}{ Sitio } & \multicolumn{2}{|c|}{ Entierro } & \multicolumn{3}{c|}{ Tipo } & \\
\cline { 2 - 6 } & Simple & Múltiple & Directo & Cista & Urna & TOTAL \\
\hline Muyuna & 3 & 4 & 7 & - & - & 7 \\
\hline Keta Kara & 6 & 13 & 3 & 16 & - & 19 \\
\hline La Isla & 9 & 21 & 28 & - & 2 & 30 \\
\hline TOTAL & 18 & 38 & 38 & 16 & 2 & 56 \\
\hline
\end{tabular}

Fuente: Datos propios

PDRII: para este período se registra (Tabla 7) que la modalidad de entierro es en su mayoría de tipo simple (57.48\%). También es alta la frecuencia de estructuras funerarias con más de un individuo (40.72\%). Cuando se observan los tipos de entierro la modalidad que mayor presencia tiene es la cista $(59.28 \%)$ mientras que, en mucha menor frecuencia, hay individuos enterrados directamente en el suelo (16.77\%) y en urnas $(2.40 \%)$.

Tabla 7 - Tipos entierro Período PDR II

\begin{tabular}{|l|r|r|r|r|r|r|r|r|}
\hline & \multicolumn{4}{|c|}{ Entierro } & \multicolumn{5}{c|}{ Tipo } & \\
\cline { 2 - 9 } \multicolumn{1}{c|}{ Sitio } & Simple & Múltiple & S/d & $\begin{array}{c}\text { Di- } \\
\text { recto }\end{array}$ & Cista & Urna & S/d & TOTAL \\
\hline Juella & 23 & 2 & 3 & 3 & 9 & 14 & 2 & 28 \\
\hline Yacoraite & 8 & 18 & - & 2 & 23 & 1 & - & 26 \\
\hline Los Amarillos & 2 & 4 & - & 2 & 3 & 1 & - & 6 \\
\hline Peñas Blancas & 18 & 8 & - & 13 & 7 & 4 & 2 & 26 \\
\hline Pucara de la Cueva & 2 & 1 & - & 1 & 2 & - & - & 3 \\
\hline Ciénega Grande & 15 & 1 & - & - & 12 & 4 & - & 16 \\
\hline Campo Morado & 3 & 4 & - & 2 & 5 & - & - & 7 \\
\hline La Huerta & 12 & 13 & - & 3 & 17 & 5 & - & 25 \\
\hline Pucara de Tilcara & 13 & 17 & - & 2 & 21 & 7 & - & 30 \\
\hline \multicolumn{1}{|r|}{ TOTAL } & 96 & 68 & 3 & 28 & 99 & 36 & 4 & 167 \\
\hline
\end{tabular}

Fuente: Datos propios

\section{Discusión}

Las prácticas mortuorias en Quebrada de Humahuaca en sus diferentes momentos de ocupación antes del arribo y conquista del imperio incaico en el año 1436 d.C., tuvieron características comunes a lo largo del tiempo. Una de ellas es que, a diferencia de lo que sucede 
en otras regiones del NOA como los valles calchaquíes, no hay urnas exclusivamente diseñadas y decoradas para uso fúnebre sino que se utilizaron vasijas cerámicas de uso cotidiano.

Otra cualidad que permanece a lo largo del tiempo es que se habría dado una cercanía de estos espacios funerarios con los domésticos, no existiendo separación física marcada entre el mundo de los vivos y el de los muertos, salvo dos casos en el PDR II. Esto ha sido interpretado en el sentido que el mundo de los muertos era una parte constitutiva de la experiencia cotidiana, no estaban alejados de la vida diaria de forma tal que los deudos tenían que trasladarse a la tumba del difunto sino que la misma formaba parte de esa esfera diaria de interacción social (Acuto et al., 2011). Al mismo tiempo esta convivencia entre los vivos y los difuntos podría considerarse que "otorgan sentido de pertenencia, comunidad, perpetuidad, memoria e identidad" (Ortiz y Nieva, 2015, p. 161).

En este proceso también se registran particularidades que merecen ser destacadas.

\section{Período Formativo}

Para este período se registraron pocas piezas cerámicas y más de la mitad del acompañamiento lo constituyen las puntas de proyectil. Siendo que se trata de período caracterizado por la ausencia de un poder centralizado y de desigualdades estructurales (Nielsen, 2001), sería de esperar que no hubiera gran conflictividad social; sin embargo el hecho de la presencia de puntas de proyectil como acompañamiento mortuorio sumado a que en Til 20 se halló una punta de proyectil incrustada en el talón de uno de los individuos (Bordach et al., 1999; Mendonça et al., 1991; Mendonça et al., 2002), estaría señalando algún tipo de violencia interpersonal para el período. Si bien las puntas pudieron haber sido utilizadas principalmente para actividades de caza, la evidencia de Til 20 indicaría que por lo menos en un caso se dio algún tipo de situación conflictiva. No hay que descartar que al ser pocos los casos analizados haya algún tipo de sesgo ya que en general se trata de sitios de baja visibilidad que no han podido excavarse más que en algunos pocos sectores.

El segundo grupo más representado dentro del acompañamiento lo constituyen los adornos corporales, cuentas de collar, brazaletes y anillos. Esto llama la atención en el sentido de que no hay prácticamente representación de objetos de uso cotidiano o doméstico, salvo como vimos la presencia de las puntas que podrían tener doble función de caza y como armas en situaciones de violencia interpersonal.

Respecto a la ubicación, dada la escasez de excavaciones sistemáticas para este período, sabemos, por trabajos de arqueología de rescate en el ejido urbano de Tilcara (Bordach et al., 1999; Mendonça et al., 1991; Mendonça et al., 2002) así como por las investigaciones realizadas por Salas en Estancia Grande (Salas, 1948; Palma y Olivera, 1992/1993), que los difuntos eran enterrados en espacios domésticos (Nielsen, 2001; Zaburlín et al., 2006), en su mayoría en entierros con más de un individuo y que se alternaban las modalidades de utilización de contenedores como cistas, urnas o directamente en el suelo sin preparación previa del 
espacio. A su vez en el caso de Flores se registró que uno de los espacios fue reutilizado (Seldes y Gheggi, 2016), lo cual concuerda con lo hallado en sitios del mismo período como Til-20 (Bordach et al., 1999; Mendonça et al., 1991; Mendonça et al., 2002).

Los difuntos, no permanecían solos en sus sepulturas ya que eran enterrados en grupos de dos o más, en espacios domésticos y acompañados de objetos ofrendados en los rituales funerarios.

\section{PDR I}

De acuerdo a lo visto para este período, la mayoría (67.86\%) de los difuntos han sido enterrados con algún tipo de acompañamiento. A su vez se observa que fue la cerámica la ofrenda con más representación en el repertorio del acompañamiento mortuorio $\mathbf{7 4 . 2 7 \%}$ del total), a diferencia del período anterior en el cual predominaban los objetos no utilizados en el cotidiano. En este sentido, la presencia de vasijas cerámicas, como parte del acompañamiento mortuorio, ha sido asociado a la práctica de darle comida y bebida a los ancestros como característica de muchas sociedades prehispánicas andinas (Nielsen y Boschi, 2007). El aumento de la cerámica en el registro funerario podría ser parte de la importancia que fue adquiriendo el culto a los ancestros en las sociedades quebradeñas (Nielsen, 2007).

Una de las características más relevantes de los resultados obtenidos para este periodo, es el incremento en forma considerable de la cantidad de ofrendas, en este sentido, mientras que en el período anterior la proporción es de 0.74 ofrendas por individuo, en el PDR I es de 2.92 .

La novedad es la aparición de objetos de oro, considerados bienes suntuarios de acuerdo a la literatura arqueológica (Nielsen, 2001), lo cual daría cuenta de cierta importancia que estarían adquiriendo los bienes de prestigio para la demostración de poder, punto que se asocia con lo que se discute a continuación.

Un punto interesante lo constituye las diferencias entre el acompañamiento mortuorio entre los sitios, siendo La Isla el que más ofrendas tiene en todas las categorías, y en la cerámica el predominio más notable (Tabla 3). Como se mencionó con anterioridad, es de resaltar el caso de la tumba 11 de La Isla que contiene un individuo junto a un acompañamiento compuesto de 64 piezas de cerámica y 25 de oro, lo que indica una gran cantidad de ofrendas que acompañan al difunto (Seldes y Gheggi, 2016). La abundancia de bienes de prestigio en esta tumba, especialmente las piezas de oro, sumado a la ausencia de ofrendas en otras ha sido interpretado como parte de ceremonias de ostentación en luchas por el prestigio y por el poder (Nielsen, 2001; Tarragó et al., 2010). Mientras algunas tumbas contienen gran cantidad de ofrendas hay otras en las que no hay nada, lo cual podría indicar un momento donde la diferenciación social estaría emergiendo (Seldes y Gheggi, 2016).

Igual que en el período anterior, los entierros parecen haberse realizado en espacios domésticos en entierros múltiples. Si bien Debenedetti (1910) menciona que en La Isla habrían existido necrópolis, ya hemos hecho referencia a investigaciones que concluyen que se trata 
de entierros realizados en espacios de uso doméstico (Rivolta, 2000).

Una característica propia de este período es la preparación de los espacios funerarios ya que, salvo en Keta Kara que habría que continuar analizando para evaluar sus diferencias con otros sitios del período, en su mayoría son entierros directos en el suelo, sin que se hayan elaborado estructuras para tal fin. El procedimiento consistía en cavar un pozo en el suelo para luego depositar a los difuntos con su acompañamiento para sellarlo finalmente con una capa de barro (Nielsen, 2001). Este tipo de entierros con poca inversión de trabajo se contrapone con algunos de los entierros con gran cantidad de acompañamiento, lo cual podría estar indicando que la energía en este período estaba puesta en las ofrendas y no tanto en los espacios funerarios.

\section{PDR II}

En este caso, al igual que en el período anterior, es la cerámica el acompañamiento más elegido para dejar junto a los difuntos (56\% del total), lo cual diferencia a ambos de los sucedido en el período Formativo. Nuevamente podría pensarse que se trata de un sesgo por el reducido tamaño de la muestra de ese período y que tal diferencia no sea real.

Hay un dato que resulta también relevante y es la ausencia de puntas de proyectil entre el acompañamiento, en un momento que ha sido denominado como de "guerra endémica". Lo raro de esto es que sí aparecen en otros contextos de excavación. Por alguna razón no se ha elegido como ofrenda a las puntas. Es de resaltar que el registro bioarqueológico no estaría avalando un aumento de la violencia interpersonal en este período en comparación con los anteriores (Seldes, 2007 y 2012). Tal vez ambos puntos estén relacionados. Habrá que profundizar el análisis combinando la funebria y la bioarqueología con otras líneas de evidencia que vayan surgiendo en las investigaciones.

Una característica única del PDRII es la existencia de al menos dos asentamientos con áreas segregadas para el entierro de los difuntos (Pucará de Tilcara y Pucará de Volcán), aunque la mayoría de los enterratorios siguieron realizándose en espacios domésticos. La presencia de espacios destinados especialmente al entierro de difuntos se une al hecho de la aparición de tumbas sobreelevadas tal como sucede en el Pucará de Tilcara en la Unidad Habitacional 1 (Otero et al., 2017) y en las cistas de la unidad 400 y en las del complejo A, ambos en el sitio Los Amarillos (Taboada y Angiorama, 2003). Todo esto conforma un escenario de mayor visibilidad de los espacios mortuorios respecto de períodos anteriores. En este sentido, es interesante que la aparición de cementerios ha sido vinculado a la apropiación de territorios en sociedades de tipo corporativa, como forma de garantizar el acceso a recursos escasos así como legitimar derechos territoriales de un grupo a través de la presencia de ancestros enterrados ahí que certificarían vínculos con esos espacios (Saxe, 1970; Seldes y Gheggi, 2016). Queda pendiente explicar por qué aparecen cementerios en dos asentamientos siendo que hay registrados más de 30 poblados para el período.

Entre las diferencias con los períodos anteriores está el hecho que hay mayor frecuencia 
de entierros con un solo individuo (57.84\%) y que se retoma la modalidad de elaboración de espacios funerarios como lo son las cistas (59.28\% del total de este período).Esto marca una diferencia respecto a la decisión de priorizar el espacio privado para el entierro de los difuntos, lo cual convive con prácticas vinculadas a espacios para la depositación de los cuerpos. Siendo que se trata de sociedades corporativas, se esperaría que la práctica hacia los difuntos sea la de enterrarlos en tumbas colectivas o familiares. Esto es algo que por el momento no puede explicarse y que requiere de profundizar este tipo de estudios.

Otra característica peculiar de este período es que, a diferencia del período anterior y respecto a la cantidad de ofrendas por individuo, en el PDR II el acompañamiento vuelve a bajar a menos de un objeto por individuo (0.92) lo cual marca una gran diferencia entre el PDRI y los momentos previos y posteriores. En este sentido, de acuerdo a lo planteado por Nielsen, es posible pensar que si bien en el PDR I parecieran haberse dado casos de ostentación por la cantidad y riqueza de las ofrendas, en el PDR II esto habría sido resignificado frente al afianzamiento de las sociedades de tipo corporativas (Nielsen, 2006; Seldes, 2007) ya que, no se habrían consolidado jefaturas o señoríos en los cuales el jefe acumulaba bienes de prestigio sino que la importancia de una persona no se medía ya por la cantidad de bienes que alguien o un grupo acumulaba, sino por las redes de redistribución que articulaba. En otras palabras, se trataba de mantener el anonimato del poder conservando el control corporativo (Acuto, 2007).

Sin embargo, no se puede dejar de mencionar lo que ocurrió en el Complejo A en el sitio Los Amarillos ya que investigaciones revelaron que en el sector central del sitio habría habido un área que funcionó como centro de actividades ceremoniales con gran visibilidad desde amplias superficies del asentamiento (Nielsen y Walker, 1999). Nielsen considera que ese espacio fue estructurado de tal manera que un determinado sector social tenía acceso directo a las actividades que se realizaban mientras que otro grupo podía participar desde una plaza cercana. Lo sucedido en Los Amarillos podría ser contradictorio con lo que se dice sobre las sociedades corporativas y la no acumulación por parte de un jefe o grupo; sin embargo, estas no constituyeron construcciones monumentales que surgieran para inmortalizar a un individuo en particular; siguiendo esta idea se ha propuesto que la evidencia hallada en el Complejo A estaría dando cuenta de ceremonias públicas que no se realizarían para glorificar a alguien poderoso sino a emblemas corporativos de grupos definidos por criterios como descendencia o etnicidad (Nielsen, 2006). Por consiguiente se estaría propiciando cierto sentido de integración comunal más que de segregación de un grupo. Esto no quiere decir que no hubieran competencias por el liderazgo sino que bien pudo ser un momento de tensión entre la consolidación de un sistema corporativo y la lucha por el poder (Acuto, 2007).

También es en el PDR II, como ya se mencionó, pareciera que asume gran importancia lo que se conoce como el culto a los ancestros, esto es, el "conjunto de prácticas religiosas que permiten la intervención de los muertos en los asuntos de los vivos" (Nielsen y Boschi, 2007, p. 52). Se trata de una práctica que se dio en diferentes sociedades prehispánicas del área andina por la cual, se consideraba a los antepasados como fundadores de los ayllus, propietarios de las tierras y fuente ultima de toda autoridad. El principal referente del ancestro era el cuerpo del difunto o partes de él, los difuntos en la forma de ancestros eran los que 
mantenían el bienestar de la comunidad, garantizaban las cosechas y el ganado. Este culto en las sociedades corporativas como las que se dieron en la Quebrada de Humahuaca, funcionaba como articulador de las colectividades y como integrador dando legitimidad a los sistemas de organización sociopolítica a la vez que un argumento para la territorialidad de estos grandes grupos sociales.

\section{Conclusiones}

La combinación de diferentes aspectos de las prácticas mortuorias ha servido para demostrar que las mismas en la Quebrada de Humahuaca en tiempos prehispánicos tienen una complejidad que amerita investigarla considerando sus particularidades en los diferentes momentos de ocupación. De esta manera, no es posible generalizar y plantear una sola modalidad para la región ya que son muchas las cuestiones puestas en juego a la hora de despedir a los difuntos por parte de los grupos sociales (Carr, 1995).

Los resultados obtenidos avalan la idea ya postulada por distintos investigadores sobre la cotidianeidad con la que la muerte de los seres queridos era percibida constituyéndola parte de la vida cotidiana (Acuto et al., 2011; Seldes y Gheggi, 2016). Las poblaciones de la Quebrada privilegiaban el entierro de los difuntos en espacios compartidos para los primeros periodos considerados en este trabajo mientras que en el PDRII en general, los fallecidos se entierran en tumbas individuales.

A lo largo del tiempo conviven diferentes formas de construcción de las sepulturas, siendo que durante el PDR I se decide no invertir energía en la elaboración de los espacios funerarios pero es cuando al mismo tiempo las ofrendas se multiplican respecto al resto de los períodos, con la presencia de objetos de oro considerados bienes suntuarios. Es también en el PDR I que el acompañamiento mortuorio parece señalar un proceso de desigualdad social que luego fue clausurado en el PDR II con el afianzamiento de sociedades de tipo corporativas.

EI PDR II se caracteriza a nivel mortuorio por la aparición de espacios segregados para el entierro de individuos lo cual podría vincularse como se ha dicho a la legitimación de derechos sobre el territorio. Finalmente la evidencia funeraria no registra un aumento de violencia social lo cual coincide con los análisis bioarqueológicos.

A modo de cierre, es posible concluir que las prácticas mortuorias, como toda prácticas social, produce y reproduce las lógicas socio culturales, portan y transmiten memoria e identidad (Bettencourt, 2008) y por lo tanto pueden brindar importante información sobre los modos de vida de los pueblos.

Agradecimientos: A Florencia Botta por ayuda incondicional. A los evaluadores que con sus comentarios han permitido enriquecer el trabajo. A los editores por la ayuda y asesoramiento. 


\section{Referencias Bibliográficas}

ACUTO, Felix. Fragmentación vs. integración regional: repensando el período Tardío del Noroeste Argentino. Estudios Atacameños, San Pedro de Atacama, Chile, v. 34, p. 71-95, 2007. Disponible en: <https://doi.org/10.4067/s0718-10432007000200005>. Fecha de acceso: 13/01/2018.

ACUTO, Felix; KERGARAVAT, Marisa y AMUEDO, Claudia. Experiencias de la muerte y la representación de las personas en las prácticas funerarias del valle calchaquí norte. Comechingonia. Centro de Estudios Históricos Carlos S.A. Segreti, Córdoba, v. 14, p. 23-54, 2011. Disponible en: <https://revistas.unc.edu.ar/index.php/comechingonia/article/view/17891>. Fecha de acceso: 13/01/2018.

ALBECK, María Esther. El ambiente como generador de hipótesis sobre dinámica sociocultural prehispánica en la Quebrada de Humahuaca. Cuadernos. Facultad de Humanidades y Ciencias Sociales, Universidad Nacional de Jujuy, San Salvador de Jujuy, v. 3, p. 95-106, 1992.

ANGIORAMA, Carlos. De metales, minerales y yacimientos. Contribución al estudio de la metalurgia prehispánica en el extremo noroccidental de Argentina. Estudios Atacameños. Universidad católica del norte, San Pedro de Atacama, Chile, v. 21, p. 63-88, 2001.

ASCHERO, Carlos. El poblamiento del territorio. En: TARRAGÓ, Myriam (ed.). Nueva Historia Argentina, vol. I. Buenos Aires: Editorial Sudamericana, p. 17-59, 2000.

BAFFI, Elvira Inés. Caracterización biológica de la población prehispánica tardía del sector septentrional del valle Calchaquí (Pcia. de Salta). Tesis de doctorado. Facultad de Filosofía y Letras, Universidad de Buenos Aires, Buenos Aires. 1992. 218p.

BETTENCOURT, Ana Maria dos Santos. Life and Death in the Bronze Age of the NW of Iberian Peninsula. En: FAHLANDER, Fredrik y OESTIGAARD, Terje (eds.). The materiality of death: bodies, burials, beliefs. Oxford, BAR International Series 1768, p. 99-104, 2008.

BINFORD, Lewis. Mortuary Practices: their study and their potencial. Memoirs of the Society for American Archaeology. New York, v. 25, p. 6-29, 1971.

BORDACH, María Asunción; DALERBA, Laura y MENDONÇA, Osvaldo. Vida y Muerte en Quebrada de Humahuaca. Córdoba: Universidad Nacional de Río Cuarto, 1999. 108p.

BOURDIEU, Pierre. Outline of a theory of practice. Cambridge: Cambridge University press, 1977. 255p.

Pierre. Sociología y Cultura. México: Editorial Grijalbo, 1990. 317p.

BRUM RIBEIRO, Liliane. Limpando Ossos E Expulsando Mortos: Estudo Comparativo de Rituais Funerários em Culturas Indígenas Brasileiras Através de uma Revisão Bibliográfica. (Dissertação de Mestrado em Antropologia Social). Curso de Pós-Graduação em Antropologia Social, Centro de Ciências Humanas, Universidade Federal de Santa Catarina, 2002. 225p.

BRUMFIEL, Elizabeth. On the archaeology of choice. Agency studies as a research stratagem. En: DOBRES, Marcia Anne y ROBB, John (eds.). Agency in Archaeology. London; New York: Ed. 
Routledge, p. 249-255, 2000.

CABRERA, Angel. Regiones Fitogeográficas Argentinas. Enciclopedia Argentina de Agricultura y Jardinería, tomo II. Segunda Edición. Buenos Aires: Editorial ACME, 1976. 89p.

CARR, Edward. Mortuary practices: their social, philosophical - religious, circumstancial, and physical determinants. Journal of Archaeological Method and Theory, New York, v. 2, p. 105200, 1995. Disponible en <https://doi.org/10.1007/BF02228990>. Fecha de acceso: 12/01/2018.

CASANOVA, Eduardo. Tres ruinas indígenas en la Quebrada de la Cueva. Anales del Museo Nacional de Historia Natural "Bernardino Rivadavia", Buenos Aires, v. XXXVII, 1933, p. 255-320.

CIGLIANO, Eduardo. Investigaciones antropológicas en el yacimiento de Juella (Depto. Tilcara, Provincia de Jujuy). Revista del Museo de la Plata (Nueva Serie), La Plata, v. VI, n.34, p. 123-238, 1967.

DEBENEDETTI, Salvador. Exploración arqueológica en los cementerios prehistóricos de La Isla de Tilcara. Publicaciones de la Sección Antropología, Facultad de Filosofía y Letras, Universidad de Buenos Aires, Buenos Aires, v. 6, 1910.

Salvador. Las ruinas del Pucará, Tilcara, Quebrada de Humahuaca (Provincia de Jujuy). Archivos del Museo Etnográfico, Facultad de Filosofía y Letras, Universidad de Buenos Aires, Buenos Aires, II, p. 7-142, 1930.

DOBRES, Marcia Anne y ROBB, John. Agency in archaeology. Paradigm or platitude? En: DOBRES, Marcia Anne y ROBB, John (eds.). Agency in Archaeology. London y New York: Ed. Routledge, p. 3-17, 2000.

FAHLANDER, Fredrik y OESTIGAARD, Terje. The materiality of death: bodies, burials, beliefs. En: FAHLANDER, Fredrik y OESTIGAARD, Terje (eds.). The materiality of death: bodies, burials, beliefs. Oxford, BAR International Series 1768, p. 1-15, 2008.

FRITZ, Sherilyn; BAKER, Paul; LOWENSTIEN, Tim; SELTZER, Geoffrey; RIGSBY, Catherine; DWYER, Gary; TAPIA, Pedro; ARNOLD, Kimberly; KU, Teh-Lung y LUO, Shangde. Hydrologic variation during the last 170.000 years in the southern hemisphere tropics of South America. Quaternary Research, 61, p. 95-104, 2004.<DOl:10.1016/j.yqres.2003.08.007>.

GATTO, Santiago. Exploraciones arqueológicas en el Pucara de Volcán. Revista Museo de La Plata (nueva serie). Sección Antropología, La Plata, v. IV, n. 18, 1946.

HODDER, Ian. Posprocessual Archaeology. Advances in Archaeological Method and Theory, New York, v. 8, p. 1-26, 1995. Disponible en: <https://doi.org/10.1016/B978-0-12-0031085.50006-3>. Fecha de acceso: 10/04/2015.

HORTA TRICALLOTIS, Helena. El estilo circumpuneño en el arte de la parafernalia alucinógena prehispánica (Atacama y Noroeste Argentino). Estudios atacameños, v.4, p. 35-34, 2012. San Pedro de Atacama. Disponible en: <http://dx.doi.org/10.4067/S0718-10432012000100002>. Fecha de acceso: 01/2018.

IMBELLONI, José. Tabla Clasificatoria de Indios. Physis, Buenos Aires, v. XII, p. 229-249, 1938.

MADRAZO, Guillermo. Alfarería prehumahuaca en Tilcara (Quebrada de Humahuaca, Prov. de 
Jujuy). Etnia, Museo Etnográfico Municipal Dámaso Arce, Olavarría, v. 8, p. 16-18, 1968.

MENDONÇA, Osvaldo; BORDACH, María Asunción; ALBECK, María Esther y RUIZ, Martha. Ambiente, comunidad y comportamiento biosocial en el Formativo de Tilcara, Quebrada de Humahuaca, Jujuy. Pacarina, Universidad Nacional de Jujuy, Jujuy, v. 2, n. 2, p. 135-147, 2002.

BORDACH, María Asunción; RUIZ, Martha y CREMONTE, Beatriz. Nuevas evidencias del período agroalfarero temprano en Quebrada de Humahuaca. Los hallazgos del sitio Til 20 (Tilcara, Jujuy). Comechingonia, Córdoba, v. 7, p. 31-45, 1991.

MILLER, Daniel y TILLEY, Christopher. Ideology, power and prehistory: an introduction. En: MILLER, Daniel y TILLEY, Christopher (eds.). Ideology, Power and Prehistory. Cambridge University press, Cambridge, p. 1-15, 1984.

MOSELEY, Michael. The Incas and their Ancestors: The Archaeology of Peru. Revised Edition. London: Thames \& Hudson Ltd., 2001. 288p.

NIELSEN, Axel. Evolución social en Quebrada de Humahuaca (AD 700-1536). En: y Eduardo BERBERIÁN (eds.). Historia Argentina prehispánica, tomo 1, Editorial Brujas, Córdoba, p. 171-264, 2001.

Plazas para los antepasados: descentralización y poder corporativo en las formaciones políticas preincaicas de los Andes circumpuneños. Estudios Atacameños, San Pedro de Atacama, Chile, v. 31, p. 63-89, 2006. Disponible en: < http//10.4067/S071810432006000100006>. Fecha de acceso: 13/01/2018.

Armas Significantes: Tramas Culturales, Guerra y Cambio Social en el Sur Andino Prehispánico. Boletín del Museo Chileno de Arte Precolombino, Chile, v. 12, p. 9-41, 2007. Disponible en: <http://www.redalyc.org/articulo.oa?id=359933355002>. Acceso en: 28/05/2018.

El estudio de la guerra en la arqueología sur- andina. Corpus Archivos virtuales de la alteridad americana, Buenos Aires, v. 5, n. 1, 2015. <DOI: 10.4000/corpusarchivos.1393>.

y Lucio BOSCHI. Celebrando con los antepasados. Arqueología del espacio público en Los Amarillos, Quebrada de Humahuaca, Jujuy, Argentina. Jujuy: Ediciones Mallku, 2007. $132 \mathrm{p}$.

y William WALKER. Conquista Ritual y Dominación Política en el Tawantinsuyu: El caso de Los Amarillos (Jujuy, Argentina). En: ZARANKIN, Andrés y ACUTO, Felix (eds.). Sed Non Satiata. Teoría Social en la Arqueología Latinoamericana Contemporánea. Buenos Aires: Ediciones Tridente, p.153-169, 1999.

ORTIZ, Gabriela y NIEVA, Luis. Rituales y memorias del pasado. Prácticas funerarias en la región del río San Francisco, Jujuy, Argentina. En: SELDES, Verónica y GHEGGl, María Soledad (eds.), Antropología biológica y estudios del comportamiento mortuorio de los pueblos prehispánicos del noroeste Argentino. Buenos Aires: Fundación Azara, p. 149-174, 2015.

OTERO, Clarisa; BORDACH, María Asunción y MENDONÇA, Osvaldo. Las prácticas funerarias en el Pucará de Tilcara (Jujuy, Argentina). Nuevos Aportes para su conocimiento a partir del caso de la Unidad Habitacional 1. Antípoda. Revista Antropología y Arqueología. Bogotá, 27, p. 141-163, 2017. Disponible en: <https://dx.doi.org/10.7440/antipoda27.2017.06> Fecha de 
acceso: 28/05/2018.

PALMA, Jorge. Aproximación al estudio de una sociedad compleja: un análisis orientado en la funebria. Arqueología. ICA, Facultad de Filosofía y Letras, UBA, v. 3, p. 41-68, 1993.

Ceremonialismo mortuorio y registro arqueológico. Apuntes sobre complejidad social. Relaciones. Sociedad Argentina de Antropología, Buenos Aires, v. XXII/ XXIII, p. 179-202, $1997 / 98$

y OLIVERA, Daniel. Hacia la Contrastación de un Modelo Arqueologico para el Formativo Regional de Humahuaca: el caso de Estancia Grande. Cuadernos del Instituto Nacional de Antropología y Pensamiento Latinoamericano. Buenos Aires, 14, p. 237-259, 1992/93.

PAUKETAT, Timothy y ALT, Susan. Agency in Postmold? Physicality and the Archaeology of Culture - Making. Journal of Archaeological Method and Theory. Springer international publishing, v. 12, n. 3, p. 213-236, 2005. Disponible en DOI: <10.1007/s10816-005-6929-9>. Fecha de acceso: 14/01/2018.

PELISSERO, Norberto. Arqueología de la Quebrada de Juella. San Salvador de Jujuy: Dirección Provincial de Cultura de Jujuy, 1969. 98p.

El sitio arqueológico de Keta Kara. Buenos Aires: Centro Argentino de Etnología Americana, 1995. 169p.

RIVOLTA, Clara. 90 años de investigación en la Quebrada de Humahuaca: un estudio reflexivo. Tilcara: Instituto Interdisciplinario de Tilcara, FFyL-UBA, 2000. 70p.

SALAS, Alberto. El Antigal de Ciénega Grande (Quebrada de Purmamarca. Prov. de Jujuy). Publicaciones del Museo Etnográfico. Facultad de Filosofía y Letras, serie A, Universidad de Buenos Aires, Buenos Aires, v. V, p. 7-268, 1945.

Un Nuevo Yacimiento Arqueológico en la Región Humahuaca. Actas y Memorias XXVIII Congreso Internacional de Americanistas. Paris, p. 643-648, 1948.

SAXE, Arthur. Social dimensions of mortuary practices. Ph. D. Dissertation, University of Michigan, University Microfilms, Ann Arbor, 1970. 235p.

SELDES, Verónica. Aportes de la bioarqueología al estudio de la complejidad y la desigualdad social en la Quebrada de Humahuaca (Jujuy, Argentina). Tesis Doctoral, Facultad de Filosofía y Letras, Universidad de Buenos Aires, Buenos Aires, 2007. 286p.

Más allá de la adaptación. La interpretación del registro bioarqueológico. Anuario de Arqueología. Escuela de Antropología, Facultad de Humanidades y Artes, Universidad Nacional de Rosario, v.1, p. 109-118, 2009.

Hacia una bioarqueología social. La Quebrada de Humahuaca en perspectiva histórica. España: Editorial Académica Española, 2012. 176p.

y GHEGGI, María Soledad. Prácticas Mortuorias en Quebrada de Humahuaca CA. 500-1550 AD. Revista Andes. Salta, v.27, 2016. Disponible en: $<$ http://www.redalyc.org/articulo. oa?id=12749260012>. Fecha de acceso: 28/05/2018. 
SHIMADA, Izumi; SCHAAF, Crystal; THOMPSON, Lonnie G. y MOSLEY- THOMPSON, Ellen. Cultural impacts of severe droughts in the prehistoric andes: application of a 1500 - year ice core precipitation record. World Archaeology, n. 22, p. 247-270, 1991. Disponible en: http:// www.jstor.org/stable/124787. Fecha de acceso: 28/05/2018.

TABOADA, Constanza y ANGIORAMA, Carlos. Buscando los indicadores arqueológicos de la unidad doméstica. Cuadernos, Facultad de Humanidades y Ciencias Sociales, Universidad Nacional de Jujuy. San Salvador de Jujuy, n. 20, p. 393 - 407, 2003.

TAINTER, Joseph. Mortuary practices and the study of prehistoric social systems. Advances in Archaeological Method and Theory, v. 1, p. 105-141, 1978.

TARRAGÓ, Myriam; GONZALEZ, Luis; AVALOS, Gimena y LAMAMÍ, Marcelo. Oro de los señores. La Tumba 11 de La Isla de Tilcara (Jujuy, Noroeste Argentino). Boletín Del Museo Chileno De Arte Precolombino, Santiago de Chile, Chile, v. 15, n. 2, p. 47-63, 2010. Disponible en: <http// doi.org/10.4067/s0718-68942010000200004>. Fecha de acceso: 28/05/2018.

THOMPSON, Lonnie. G.; MOSLEY-THOMPSON, Ellen; BOLZAN, John F. y KOCl, B. R.. A 1500year record of tropical precipitation in ice cores from the Quelcaya Ice Cap, Perú. Science, 229, p. $971973,1985 .<$ DOl:10.1038/336763a0>.

VAN POOL, Christine y VAN POOL, Todd. The scientific nature of postprocessualism. American Antiquity, Washington, v. 64, n.1, p. 33-53, 1999. Disponible en DOI: <https://doi. org/10.2307/2694344>. Published online: 20 January 2017. Fecha de acceso: 28/05/2018.

YACOBACCIO, Hugo D. Intercambio y caravanas de llamas en el sur andino (3000-1000 AP). Comechingonia, v. 16, p. 31-51, 2012.

ZABURLÍN, María Amalia; SELDES, Verónica y MERCOLLI, Pablo. Reflexiones sobre los últimos rescates arqueológicos en Tilcara. En: AUSTRAL, Antonio y TAMAGNINI, Marcela (comps.). Problemáticas de la Arqueología Contemporánea. Córdoba: Universidad Nacional de Río Cuarto, p. 325-349, 2006.

Recebido em: 01 de fevereiro de 2018

Aprovado em: 21 de maio de 2018 